\title{
Héctor Mario Pucciarelli, 1939-2018
}

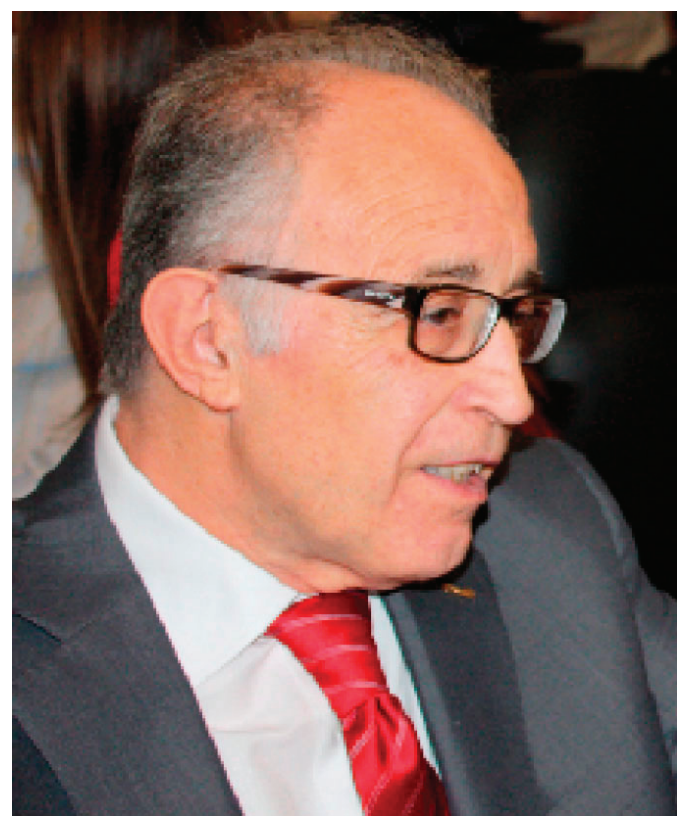

Foto gentileza de María Cristina Muñe.

Héctor Mario Pucciarelli falleció el pasado 27 de noviembre en la ciudad de La Plata, la misma que lo vio nacer y a la que amaba. Lo acompañaba su esposa, María Cristina Muñe, quien desde que se conocieron siempre estuvo a su lado.

Héctor Pucciarelli se graduó como Licenciado en Antropología en 1967 en la Facultad de Ciencias Naturales y Museo, de la Universidad Nacional de La Plata (UNLP) y en 1971 como Doctor en Ciencias Naturales en la misma institución. También en esa casa de estudios y siendo estudiante, en 1965 comenzó a hacer docencia en la cátedra de Fundamentos de Antropología. Luego llegaría a ser profesor titular en la cátedra de Antropología Biológica I, cargo que ejerció de 1983 a 2010. En 1975 ingresó a la Carrera de Investigador Científico del Consejo Nacional de Investigaciones Científicas y Técnicas y se jubiló al cabo de unas décadas como Investigador Superior, máxima jerarquía a la que se puede aspirar en ese organismo.

Héctor fue mi profesor en 1990. En 1996, cuando buscaba comenzar mis actividades de investigación y Héctor ya era Jefe de la División Antropología del Museo de La Plata, me abrió las puertas de su despacho y fue mi director. $\mathrm{La}$ entrega a su vocación fue de tal relevancia, para mí como para muchos discípulos y colegas, que resulta difícil volcar en palabras la magnitud del investigador, docente, colega, amigo o, mejor aún, del hombre que trabajó para ver, saber y transformar la disciplina y las instituciones donde se desempeñó. Para apreciar sus contribuciones científicas y su trayectoria invito a leer el libro que se hizo en su homenaje "De como cruzar fronteras en la ciencia. Un homenaje a Héctor Mario Pucciarelli" (compilado por Carolina Paschetta y colaboradores, 2017) del cual participaron antropólogos que lo conocieron de distintas maneras.

Trabajó con afán denodado. Basta tener en cuenta que luego de su tesis doctoral, titulada Variaciones Craneanas en Grupos Raciales Aborígenes de la República Argentina y defendida en 1971, comenzó en 1973 a publicar trabajos experimentales utilizando animales de laboratorio. Héctor Pucciarelli -el "Pucha", para muchos allegados- se hizo eco del espíritu de la Nueva Antropología Física que buscaba superar el viejo paradigma racial y tipológico y se atrevió -por controvertido que resultara en la Argentina de la década de 1970- experimentar con animales para dar respuestas a la comprensión de la variación humana; allí donde había interpretaciones tipológicas, buscó conocer los procesos. Bajo los mismos principios, se destacan también sus trabajos de crecimiento y nutrición.

Un hito relevante en su carrera fue la interacción con el investigador norteamericano Melvin Moss. Este último desarrolló la Hipótesis de la Matriz Funcional, aportando elementos fundamentales para comprender la variación ósea en términos de las interacciones entre moléculas, tejidos y órganos, superando viejos paradigmas genéticos que asumían que la morfología del esqueleto craneano resultaba de la acción genética directa. Inspirado en estos conceptos, Héctor Pucciarelli desarrolló un conjunto de mediciones localizadas en distintos componentes funcionales del cráneo que aplicó en sus tra-

doi:10.24215/18536387e001 
bajos experimentales. A partir de la década de 1990 comenzó otro trayecto audaz que fue el de trasladar conceptos y métodos desarrollados en sus trabajos experimentales a la craneometría humana.

Era esto último necesario, se preguntarán muchos, si los métodos craneométricos clásicos han dado respuestas durante más de un siglo. Héctor respondía que esos métodos permitían conocer muy poco; solo permitían medir diferencias, pero no saber dónde estaban las diferencias, y así no se podía conocer el por qué, ni las causas ni los procesos biológicos. Y allí se embarcó a dilucidar el poblamiento temprano de América y la diferenciación de los aborígenes americanos. Se animó a discutir la variación humana en escalas macro-regionales y continentales en épocas en que predominaban los estudios micro-regionales. Así, llevó adelante la construcción de una base abierta de datos craneométricos obtenidos de diversas poblaciones humanas.

Recibió reconocimientos entre los que se destacan las distinciones de Profesor Emérito de la UNLP y la de Graduado Ilustre de la misma institución, ambos en 2010. Su trayectoria y su calidad humana le permitieron ocupar lugares estratégicos que supo aprovechar para construir espacios de crecimiento académico y científico que lo trascendieran. Su rol institucional fue fundamental, por ejemplo, en la elaboración del Plan de Estudios de la carrera de Antropología de una Universidad Nacional de La Plata, una vez que llegó la democracia en 1983. Fue socio fundador y primer presidente de la Asociación de Antropología Biológica Argentina, creada en 1993. Colaboró en la organización de la Asociación Latinoamericana de Antropología Biológica. Fue Subdirector del Centro de Investigaciones en Genética Básica y Aplicada de la Facultad de Ciencias Veterinarias (UNLP) de 1991 a 1999 y Jefe de la División Antropología del Museo de La Plata (UNLP) de 1991 a 2015.

Entre sus mayores contribuciones es necesario subrayar la creación, junto con Raúl Carnese, de este espacio, la Revista Argentina de Antropología Biológica, dirigida por ambos antropólogos desde su primer volumen en 1996 hasta 2014. Sin duda, este es un ámbito de incalculable valor para quienes nos dedicamos a la antropología biológica en Argentina y también para Latinoamérica.
Héctor abrió tantas otras puertas, literales o metafóricas, para crear espacios de acción y formación. Escuchaba a quien se acercase, con la idea de realizar una tesis, pero también a personas como aquel escultor jubilado que en los años noventa solía ir a verlo a su despacho del Museo para dialogar sobre sus hipótesis acerca del origen de la escultura en relación con la evolución humana. Héctor despertó enorme cariño y respeto. Basta recordar la manera en que discípulos y colegas se han referido a él y, más aun, el entusiasmo que mostraban los estudiantes que asistieron a las Jornadas Nacionales de Antropología Biológica, en Puerto Madryn en 2009, para sacarse fotos con él. Todos lo queríamos tener cerca al "Pucha".

$\mathrm{Su}$ legado es grande. Quedan muchos discípulos en distintos lugares de Argentina. Una gran cantidad de colegas en países de Latinoamérica, Europa y en Estados Unidos se vieron inspirados por él y lo inspiraron a través de distintas formas de colaboración. Publicó más de 130 trabajos científicos y realizó muchos más aportes intangibles en sus clases, en las charlas durante las cenas de los congresos con una copa de vino en la mano o a través del diálogo en la intimidad del laboratorio, cuando compartíamos unos mates, planificando trabajos o hablando de política.

Héctor solía elucubrar en voz alta y a veces se iba por las ramas, lo normal en alguien que ve más allá y con quien se puede dialogar; dialogar de todo un poco, o mucho, no solo de ciencia, y todo con la misma inteligencia y pasión. Su amigo y colega, Raúl Carnese, lo describió como un "polemista teórico de relieve" (Carnese, 2017: 8). Tal vez por esa esencia de polemista e inconforme es que se animó a romper con las tradiciones para generar lo nuevo. De su condición de observador, buscador, de antropólogo nomás, interesado por todo lo humano es que sus lecturas abarcaban desde los templarios hasta las andanzas de Inodoro Pereyra; y en ese entrevero de gustos emergían charlas sobre música barroca, pintura italiana, anécdotas de viajes, descripción de personajes reales o literarios, así como hipótesis sobre la evolución del cráneo y el esqueleto, entre otras.

Con el correr de los años se convirtió en mi "maestro", inspirándome en aspectos que trascienden a la antropología; enseñándome a ver, 
a proceder con firmeza en las crisis y a trabajar sin perder el rumbo. Entre tantas conversaciones, rescato dos anécdotas. La primera es del año 2011, cuando fui a su despacho como tantas otras veces a conversar de los temas de investigación, del futuro, de política y me contó acerca de un nuevo tema sobre el que quería escribir un trabajo y me dijo: "Se me ocurrieron muchas cosas raras". Héctor siempre pergeñaba ideas: algunas raras, otras importantes, algunas que proliferaron e hicieron escuela, en tanto que otras quedaron en el camino. No pude evitar conectar ese recuerdo con otra cosa que me dijo muchos años antes y que me marcó significativamente, cuando yo recién empezaba a generar mis propias ideas. Un día le mostré los resultados de unos análisis estadísticos que, a mi entender, podían ser interesantes para publicar un trabajo. Héctor se entusiasmó tanto y me propuso tal cantidad de cambios sobre lo que yo había hecho que me sentía algo arrepentida de habérselo contado. Frente a mi queja me dijo: "Las ideas son como hijos, una vez que nacieron, están ahi y hay que hacerse cargo".
Ideas, trabajo constante y compromiso. ¡Gracias por tanto, Héctor! Sus ideas fueron audaces y controvertidas, pero su tenaz compromiso con ellas lo condujo a darles vida y sostenerlas, como si hubiesen sido hijas. Ahora nos toca a nosotros.

¡Hasta siempre, Comandante!

Marina L. Sardi

División Antropología, Facultad de Ciencias Naturales y Museo, Universidad Nacional de La Plata,

CONICET, Argentina.

Carnese FR. 2017. Héctor Mario Pucciarelli. Su Vida de Estudiante. En: Paschetta C, González-José R, Lanata JL, comps. De cómo cruzar fronteras en la ciencia: un homenaje a Héctor Mario Pucciarelli. Libro digital. CENPAT, IIDYPCA-CONICET. ISBN 978-987-289509-9, pp. 5-14.

Paschetta C, González-José R, Lanata JL, comps. De cómo cruzar fronteras en la ciencia: un homenaje a Héctor Mario Pucciarelli. Libro digital. CENPAT, IIDYPCACONICET. ISBN 978-987-28950-9-9 